\title{
Physical Interaction Between the Membrane (M) and Envelope (E) Proteins of the Coronavirus Avian Infectious Bronchitis Virus (IBV)
}

\author{
K. P. LIM, H. Y. XU, AND D. X. LIU \\ Institute of Molecular Agrobiology, The National University of Singapore, I Research Link, \\ Singapore 117604
}

\section{INTRODUCTION}

Coronavirus avian infectious bronchitis virus (IBV) encodes at least four structural proteins, i.e. the nucleocapsid $(\mathrm{N})$, membrane $(\mathrm{M})$, spike (S) and envelope (E) proteins. The IBV E protein was first identified in 1990 (Liu et. al., 1990) and demonstrated to be associated with the virion envelope (Liu and Inglis, 1991). Several studies on the two other members of the coronavirus family, namely Mouse Hepatitis Virus (MHV) and Transmissible Gastroenteritis Virus (TGEV), have indicated that E is likely to play a crucial role in viral assembly (Fischer et. al., 1998; Baudoux et. al., 1998). Together with M, E was demonstrated to be the minimal machinery required for the formation of Virus-Like Particles (VLPs) (Vennema et al, 1996). Recent reports took a step further in demonstrating that expression of $\mathrm{E}$ alone could lead to the release of VLPs (Maeda et. al., 1999; Raamsman et. al., 2000; Corse and Machamer, 2000). 


\section{MATERIAL AND METHODS}

\subsection{Transient expression of IBV sequences in Cos-7 cells}

IBV sequences placed under the control of a $\mathrm{T} 7$ promoter were transiently expressed in mammalian cells using the recombinant vaccinia virus (vTF7-3) system as described before (Liu et al., 1991). In this study, the transfection reagent used was Lipofectin (Life Technologies).

\subsection{Radioimmunoprecipitation}

Media of transfected cells were collected and mixed with $5 \mathrm{X}$ radioimmunoprecipitation assay (RIPA) buffer and precleared by centrifugation at $4,000 \mathrm{~g}$ for $30 \mathrm{~min}$ at $4^{\circ} \mathrm{C}$ in a microfuge. Cells were lysed with 1 X RIPA buffer and precleared by centrifugation at 12,000 rpm. Immunoprecipitation with anti-E and anti-M rabbit polyclonal antisera (Liu and Inglis, 1991; Ng and Liu, 2000) and anti-T7 (Novagen) was carried out as previously described (Liu et. al., 1991).

\subsection{SDS-polyacrylamide gel electrophoresis (SDS- PAGE)}

Electrophoresis of viral polypeptides was performed on SDS-17.5\% polyacrylamide gels (Laemmli, 1970). The $\left[{ }^{35} \mathrm{~S}\right]$-labeled polypeptides were detected by autoradiography.

\subsection{Immunofluorescence and confocal microscopy}

IBV sequences were transiently expressed in Cos-7 cells grown on 4-well chamber slides (IWAKI). At $5 \mathrm{~h}$ post-transfection, cells were rinsed with phosphate-buffered saline (PBS) and subjected to fixation using $4 \%$ paraformaldehyde for 15 mins and then permeabilized with $0.2 \%$ Triton-X. Fluorescence staining was performed by incubating cells with either antibody or a mixture of both primary antibodies [rabbit anti-M (1:30) or mouse anti-T7 (1:200) ] for $1 \mathrm{~h}$ at room temperature, followed by fluorescein isothiocyanate (FITC)- or tetramethyl rhodamine isocyanate (TRITC)conjugated secondary antibodies for $1 \mathrm{~h}$ at $4^{\circ} \mathrm{C}$. Goat anti-rabbit was used at 1:400 (Sigma) and goat anti-mouse IgG at 1:20 (DAKO). Images were viewed and collected with a confocal laser-scanning microscope (Zeiss). 


\subsection{Polymerase Chain Reaction (PCR)}

Appropriate primers and template DNAs were used in amplification reactions with Pfu DNA polymerase (Stratagene) under the standard buffer conditions with $2 \mathrm{mM} \mathrm{MgCl}_{2}$.

\subsection{Construction of plasmids}

Plasmid pIBVM-1 which covers the IBV sequence between nucleotides 24498 and 25159 was constructed by cloning a PvuII/SacI-digested PCR fragment, generated using primers LDX59 (5'-CAGCAACAGCTGAAGATGCCCAACG-3') and LDX60 (5'-CTACACACGAGCTCTTATGTGTAAAGA-3') into PvulI/SacI digested pKTO vector. This plasmid was digested with BglII and EcoRI to give a $661 \mathrm{bp}$ fragment which was subsequently cloned into a BglII/EcoRI-digested pGFPCl vector (CLONTECH), to give pGFPM. A 735 bp fragment, obtained by PCR using LDX55 (5'-GATTGTTCAGGCCATGGTGAATTTATTGAA-3') and XIANG8 (5'-GCACCATTGGCACACTC-3'), was digested with NcoI and BamHI and ligated into NcoI/BamHI-digested pKTO, resulting in pIBVE which contained the IBV sequence between nucleotides 24205 and 24795 . The same PCR fragment was digested with BglII and SmaI and cloned into pT7Ф10 vector, to give pT7E fusion construct. Plasmid pT7Ф10, which contains the $\mathrm{T} 7$ tag was constructed by cloning an Ncol/HindIII fragment from pET3d (Novagen) into Ncol/HindIII digested pKTO vector. Deletions made in the E protein was indicated in Figure 2a.

\section{RESULTS}

\subsection{The putative second transmembrane domain of $E$ was responsible for the physical interaction with $M$}

While coronavirus $\mathrm{M}$ and $\mathrm{E}$ proteins were shown to be the minimal essential components for VLP formation, we demonstrated that antiserum raised against $\mathrm{M}$ (anti-M) could coimmunoprecipitate a T7-tagged $\mathrm{E}$ (T7E) (Fig.1a, lane 5). Specific anti-T7 antibody could also coimmunoprecipitate $\mathrm{M}$ when cells were co-transfected with plasmids expressing T7E and $\mathrm{M}$.

$\mathrm{E}$ consists of 109 amino acids. To determine the domain(s) required for the physical interaction with $\mathrm{M}$, a series of deletion mutants of $\mathrm{E}$, as shown in Fig. $1 \mathrm{~b}$, was constructed. T7E $\Delta$ NT contains a deletion at the N-terminus between amino acid residues 1 and 14; T7E $\Delta \mathrm{TM} 1$ contains a deletion 
between nucleotides 18 and 33; T7E $\triangle \mathrm{TM} 2 \mathrm{a}$ has a deletion between residues 34 and 51 , whereas T7E $\Delta \mathrm{TM} 2 \mathrm{~b}$ contains a deletion between nucleotides 50 and 63. T7E $\Delta$ mid contains deletion between residues 67 and 84, and $\mathrm{T} 7 \mathrm{E} \Delta \mathrm{CT}$ is a mutant $\mathrm{E}$ lacking the $\mathrm{C}$-terminus from residues 83 onwards. As predicted by a computer programme, T7E $\Delta \mathrm{TM} 1$ deletes the first transmembrane domain of $\mathrm{E}$, while T7E $\Delta \mathrm{TM} 2 \mathrm{a}$ and T7E $\Delta \mathrm{TM} 2 \mathrm{~b}$ delete the first and second half of the second putative transmembrane domain, respectively, and $\mathrm{T} 7 \Delta \mathrm{CT}$ deletes a putative ER localization signal (data not shown).

Using the coimmunoprecipitation approach, we were able to determine that the second putative transmembrane domain of $\mathrm{E}$ was likely to be responsible for complex formation in vivo with $\mathrm{M}$. Most mutants could be coimmunoprecipitated with M, except for T7E $\Delta$ TM2a (Fig. 1c, lanes 5 and 12), where only trace amounts of T7E $\Delta \mathrm{TM} 2 \mathrm{a}$ and $\mathrm{M}$ could be detected using anti-M and anti-T7, respectively.

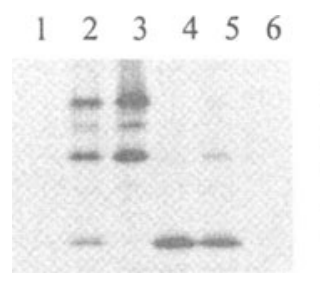

Figure la. CoIP of M and T7E
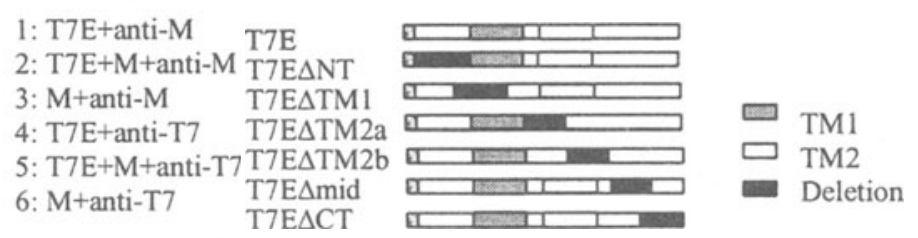

Figure $1 b$. Diagram of various deletion mutants

$\begin{array}{llllllllllllll}1 & 2 & 3 & 4 & 5 & 6 & 7 & 8 & 9 & 10 & 11 & 12 & 13 & 14\end{array}$

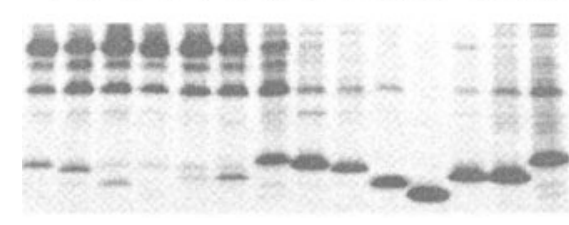

1: $\mathrm{M}+\mathrm{T} 7 \mathrm{E}+$ anti-M

2: $\mathrm{M}+\mathrm{T} 7 \mathrm{E} \Delta \mathrm{NT}+$ anti-M

3: $\mathrm{M}+\mathrm{T} 7 \mathrm{E} \Delta \mathrm{TM} 1+$ anti-M

4: M+T7E $\Delta T M 2 a+a n t i-M$

5: M+T7E $\Delta$ TM2b+anti-M

6: $\mathrm{M}+\mathrm{T} 7 \mathrm{E} \Delta \mathrm{mid}+$ anti-M

7: $\mathrm{M}+\mathrm{T} 7 \mathrm{E} \Delta \mathrm{CT}+\operatorname{anti-M}$
8: $\mathrm{M}+\mathrm{T} 7 \mathrm{E}+$ anti-T7

9: $\mathrm{M}+\mathrm{T} 7 \mathrm{E} \Delta \mathrm{NT}+\operatorname{anti}-\mathrm{T} 7$

10: M+T7E $\Delta$ TM1+anti-T7

11: $\mathrm{M}+\mathrm{T} 7 \mathrm{E} \Delta \mathrm{TM} 2 \mathrm{a}+\mathrm{anti}-\mathrm{T} 7$

12: $\mathrm{M}+\mathrm{T} 7 \mathrm{E} \Delta \mathrm{TM} 2 \mathrm{~b}+$ anti-T7

13: $\mathrm{M}+\mathrm{T} 7 \mathrm{E} \Delta \mathrm{mid}+\operatorname{anti}-\mathrm{T} 7$

14: $\mathrm{M}+\mathrm{T} 7 \mathrm{E} \Delta \mathrm{CT}+$ anti-T7

Figure 1c. Coimmunoprecipitation of $\mathrm{M}$ and mutant $\mathrm{E}$ proteins

\subsection{Effects of deletion within $E$ on the release of VLPs}

Figures $2 \mathrm{a}$ and $2 \mathrm{~b}$ show that by tagging of the $\mathrm{T} 7 \mathrm{tag}$ to $\mathrm{E}$ did not affect the VLP release. Figure $2 c$ shows the effects of deletion within $E$ on VLP release. At least a $50 \%$ drop in VLP detection was observed when the $\mathrm{N}$ terminal 14 amino acids (lane 12), the first putative transmembrane domain (lane 13) and the second putative transmembrane domain (lane 14) were 
deleted. Deletion of the C-terminal 26 amino acids (lane 17) had the most detrimental effect on VLP release.

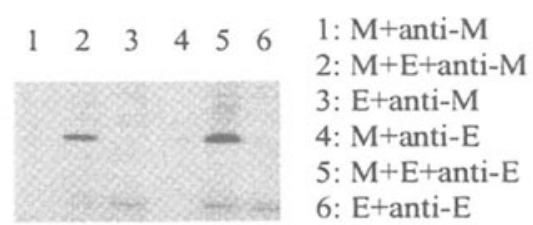

Figure 2a. Release of E from cells expressing $\mathrm{E}$

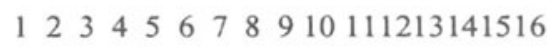

Figure 2c. Release of $\mathrm{E}$ and its deletion mutants

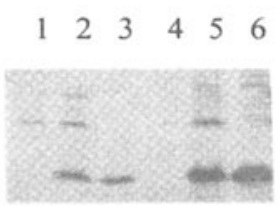
1: $\mathrm{M}+$ anti-M
2: $\mathrm{M}+\mathrm{T} 7 \mathrm{E}+$ anti-M
3: $\mathrm{T} 7 \mathrm{E}+$ anti-M
4: $\mathrm{M}+$ anti-T7
5: $\mathrm{M}+\mathrm{T} 7 \mathrm{E}+$ anti-T7
6: T7E+anti-T7

Figure $2 b$. Release of T7E from cells expressing T7E

\subsection{M could be incorporated into VLPs by non-specific interactions with $\mathbf{E}$}

Although $E$ was demonstrated to physically interact with $M$ via the second putative transmembrane domain, we do not rule out the possibility that both proteins could interact by weak hydrophobic interactions. To detect trace amounts of $\mathrm{M}$ incorporated into VLPs, we performed immunoprecipitation of precleared media using a mixture of anti-M and anti$\mathrm{T} 7$ antisera. Bands corresponding to $\mathrm{M}$ were coimmunoprecipitated with T7E (Fig.3 lane 9), T7E $\Delta$ NT (lane 10), T7E $\Delta$ TM2b (lane 13) and T7E $\Delta$ mid (lane 14), indicating that $\mathrm{M}$ was released into the media. Taken into account that less VLPs containing T7E $\Delta \mathrm{TM} 1$ (Fig.2c, lane 13) and T7 $\Delta \mathrm{CT}$ (lane 17) were detected, the amounts of $\mathrm{M}$ incorporated by these two mutants (Fig. 3, lane 11 and 15) were comparable to T7E (lane 9). However, trace amounts of $\mathrm{M}$ protein could also be coimmunoprecipitated with T7E $\Delta \mathrm{TM} 2 \mathrm{a}$ (which lacks the second putative transmembrane domain required for interaction).
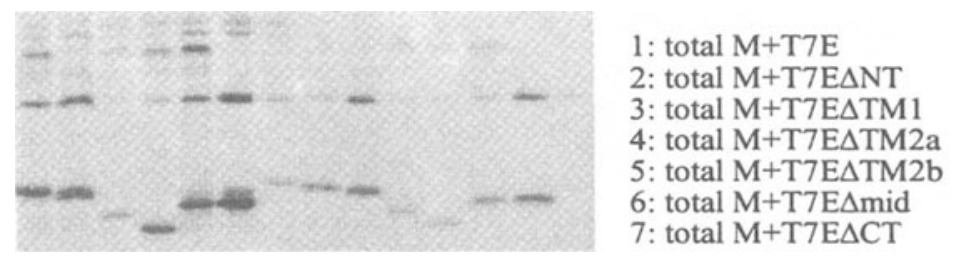

Figure 3. Release of VLPs with M incorporated 


\subsection{E protein is able to retain $M$ in the compartment it resides in}

Previous reports showed that $\mathrm{M}$ was localized to the Golgi compartment (Machamer et.al., 1990). Similar observations were shown in Figure 4A. The staining patterns of T7E, T7E $\Delta \mathrm{TM} 1, \mathrm{~T} 7 \mathrm{E} \Delta 2 \mathrm{a}$ and T7E $\Delta \mathrm{CT}$ were shown in $\mathrm{B}$ to E. Colocalization of T7E (Fig. 5A) and T7E $\Delta$ TM2a (5C) with the endoplasmic reticulum (ER), were indicated by the merged images ( $F, C$ and I). The ER was stained using R6 (Rhodamine B hexylester chloride, Molecular Probes). However, mutants T7E $\Delta$ TM (D) and T7E $\Delta C T$ (J) were not localized to the ER ( $F$ and $\mathrm{L}$ ).

The physical interaction between $\mathrm{M}$ and $\mathrm{E}$ was further indicated by the colocalization of $\mathrm{M}$ and the deletion mutants of $\mathrm{E}$. Coexpression of $\mathrm{M}$ and $\mathrm{E}$ in Cos-7 cells led to the detection of $\mathrm{M}$ in the same subcellular compartment as T7E (Fig.6A to C). When expressed together with mutant T7E $\Delta$ TM1 (G), $\mathrm{M}$ displayed a cytoplasmic staining ( $\mathrm{E}$ and $\mathrm{F}$ ) instead. $\mathrm{M}$ was also observed to colocalize with T7E $\Delta \mathrm{TM} 2 \mathrm{a}$ and T7E $\Delta \mathrm{CT}$ (6G to I; J to L).

To further confirm that this interaction, cells were cotransfected with GFPM and T7E or T7E $\triangle$ TM1. When expressed alone, GFPM showed a profile similar to the wildtype $\mathrm{M}(7 \mathrm{~A})$. Cotransfection with T7E resulted in a perinuclear staining (7B), while transfection with T7E $\Delta \mathrm{TM} 1$ resulted in a diffuse staining (7C). These patterns are clearly different from the cells expressing GFPM alone.

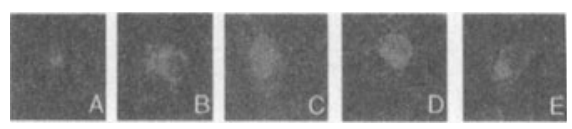

Figure 4. Subcellular localization of $\mathrm{M}(\mathrm{A})$ and $\mathrm{T} 7 \mathrm{E}(\mathrm{B})$, T7E $\Delta \mathrm{TM} 1(\mathrm{C}), \mathrm{T} 7 \mathrm{E} \Delta \mathrm{TM} 2 \mathrm{a}(\mathrm{D})$ and $\mathrm{T} 7 \mathrm{E} \Delta \mathrm{CT}(\mathrm{E})$ in transfected cells.

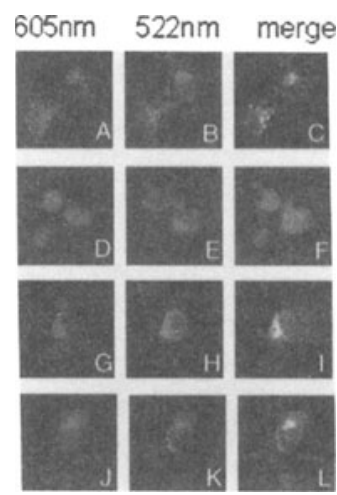

Figure 5. Colocalization of T7E(A), T7E $\Delta \mathrm{TM} 1(\mathrm{D}), \mathrm{T} 7 \mathrm{E} \Delta \mathrm{TM} 2 \mathrm{a}(\mathrm{G})$ and $\mathrm{T} 7 \mathrm{E} \Delta \mathrm{CT}(\mathrm{J})$ with the $\mathrm{ER},(\mathrm{B}, \mathrm{E}, \mathrm{H}$ and $\mathrm{J}$ ), which is stained by R6. Images $\mathrm{C}, \mathrm{F}, \mathrm{I}$ and $\mathrm{L}$ refer to merged images. 


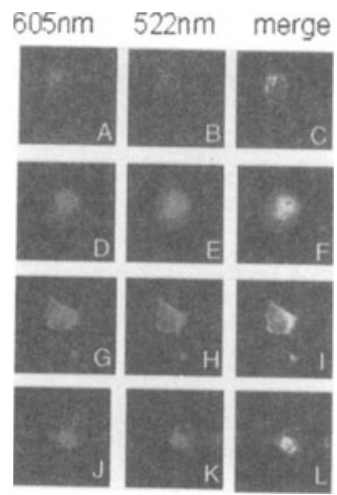

Figure 6. Dual labeling of T7E(A), T7E $\Delta \mathrm{TM} 1(\mathrm{D})$, T7E $\Delta \mathrm{TM} 2 \mathrm{a}(\mathrm{G})$ and $\mathrm{T} 7 \mathrm{E} \Delta \mathrm{CT}(\mathrm{J})$ with $\mathrm{M}$ protein, $(\mathrm{B}, \mathrm{E}, \mathrm{H}$ and $\mathrm{J})$. Images $\mathrm{C}, \mathrm{F}, \mathrm{I}$ and $\mathrm{L}$ refer to colocalization between $\mathrm{M}$ and $\mathrm{E}$.

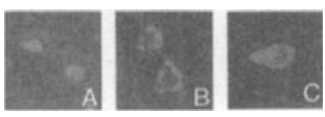

Figure 7. GFP staining of $\mathrm{M}$ when expressed alone (A), and coexpressed with $\mathrm{T} 7 \mathrm{E}(\mathrm{B})$ or $\mathrm{T} 7 \mathrm{E} \Delta \mathrm{TM} 1(\mathrm{C})$

\section{DISCUSSION AND CONCLUSION}

In this report, we presented two lines of evidence that $\mathrm{E}$ could physically interact with $\mathrm{M}$. First, in the presence of detergent and high salt content, both $\mathrm{M}$ and $\mathrm{E}$ could be coimmunoprecipitated by either specific antiserum from cells overexpressing both proteins. This method also allowed us to determine that the predicted second transmembrane domain of $\mathrm{E}$ (T7E $\Delta$ TM2a) was responsible for the interaction with M. However, we observed that when coexpressed with T7E $\Delta \mathrm{TM} 2 \mathrm{a}, \mathrm{M}$ could still be incorporated into VLPs, possibly via weak non-specific interactions. Similar conclusions could be drawn from subcellular localization studies, which provided the second line of evidence. When expressed alone, $\mathrm{M}$ was seen to be localized at the Golgi (Klumperman et. al., 1994), while at the same time, E (T7E) was observed to be located in the ER, as indicated by the staining of R6. However in cells expressing both $\mathrm{M}$ and $\mathrm{E}$, an ER-like staining pattern of $M$ was detected instead, suggesting that $E$ could retain $M$ in the ER upon physical interaction, near the site of virus budding (Klumperman et. al., 1994; Chen and Itakura, 1996). This was further reinforced by the observation that $\mathrm{M}$ displays a diffuse cytoplasmic staining similar to that of 
an $\mathrm{E}$ mutant with the first predicted transmembrane deleted (T7E $\Delta \mathrm{TM} 1$ ) upon coexpression. It was likely that this mutant had a defect in membrane insertion, and hence could not induce proper viral budding. An interesting mutant is T7E $\Delta \mathrm{CT}$, which did not show colocalization pattern with the R6stained ER compartment. The mutant protein is localized to the Golgi complex instead. Computer prediction suggested the presence of a potential ER retention signal (KDEL) at the $\mathrm{C}$-terminal region of $\mathrm{E}$. Deletion of this signal in T7E $\Delta C T$ changes the subcellular localization of $\mathrm{E}$.

\section{REFERENCES}

Baudoux, P., Carrat, C., Besnardeau, L., Charley, B., and Laude, H. 1998. Coronavirus pseudoparticles formed with recombinant $\mathrm{M}$ and $\mathrm{E}$ proteins induce alpha interferon synthesis by leukocytes. J. Virol. 72: 8636-8643.

Chen, B. Y., and Itakura, C. 1996. Cytopathology of chick renal epithelial cells experimentally infected with avian infectious bronchitis virus. Avian Pathology.25: 675-690.

Corse, E., and Machamer, C. E. 2000. Infectious bronchitis virus E protein is targeted to the golgi complex and directs release of virus-like particles. J. Virol. 74: 4319-4326.

Fischer, F., Stegen, C. F., Masters, P. S., and Samsonoff, W. A. 1998. Analysis of constructed $\mathrm{E}$ gene mutants of mouse hepatitis virus confirms a pivotal role for $\mathrm{E}$ protein in coronavirus assembly. J. Virol. 72: 7885-7894.

Furest, T. R., Niles E. G., Studier, F. W., and Moss, B. 1986. Eukaryotic transient expression system based on recombinant vaccinia virus that synthesis bacteriophage T7 RNA polymerase. Proc. Natl. Acad Sci. USA 83: 8122-8127.

Klumperman, J., Locker, J. K., Meijer, A., Horzinek, M., C., Geuze, H. J., and Rottier., P. J. M. 1994. Coronavirus accumulates beyond the site of virion budding. J. Virol. 68: 65236534.

Laemmli, U. K. 1970. Cleavage of structural proteins during the assembly of the head of bacteriophage T4. Nature 227: 680-685.

Liu, D. X., Cavanagh, P. G., and Inglis, S. C. 1991. A polycistronic mRNA specified by the coronavirus infectious bronchitis virus. Virology 184: 531-544.

Liu, D. X., and Inglis, S. C. 1991. Association of the infectious bronchitis virus 3c protein with the virion envelope. Virology 185: 911-917.

Machamer, C. E., Mentone S. A., Rose, J. K., and Farquhar, M. G. 1990. The E1 glycoprotein of an avian coronavirus is targeted to the cis golgi complex. Proc. Natl. Acad Sci. USA 87(18): 6944-6948.

Maeda, J., Maeda, A., and Makino, S. 1999. Release of coronavirus E protein in membrane vesicles from virus-infected cells and E protein-expressing cells. Virology 263: 265-272.

$\mathrm{Ng}$, L. F. P., and Liu, D. X. 2000. Further characterization of the coronavirus infectious bronchitis virus $3 \mathrm{C}$-like proteinase and determination of a new cleavage site. Virology 272: In press.

Raamsman, M. J. B, Locker, J. K., de Hooge, A. , de Vries, A. A. F., Griffiths, G., Vennema, H., and Rottier., P. J. M. 2000. Characterization of coronavirus mouse hepatitis virus strain A59 small membrane protein E. J. Virol. 74: 2333-2342.

Vennema, H., Godeke G-J, Rossen, J. W. A., Voorhout, W. F., Horzinek, M., C., Opstelten, D-J, E., and Rottier., P. J. M. 2000. Nucleocapsid-independent assembly of coronaviruslike particles by co-expression of viral envelope protein genes. EMBO J. 15: 2020-2028. 